\title{
The Influence of Systematic Bottleneck Segment on Traffic Characteristics
}

\author{
Medis Sejahtera Surbakti and Kristian Napitupulu
}

\begin{abstract}
The transportation problem causing a traffic jam in this study is a bottleneck of the road, where downstream traffic capacity is smaller than the upstream, usually, happen in the bridge entrance and where the road geometric changes such as four lanes 2 line into two lanes 2 line. This study aims to find a model that represents the mathematical relationship of volume, velocity, and density with manual count method in Jamin Ginting road, km 14.5 with four types of models named Greenshield, Greenberg, Underwood, and Bell and to determine shock wave value. The result of this research is the Greenshield model in the narrowed road which best describes the value of the independent variable (speed) to the dependent variable (density) at the location and the shock wave value at 13.00-13.15 pm $(\omega=-1.46)$, 13.15- 13.30-13.45 pm $(\omega=-1.75), 13.45-14.00 \mathrm{pm}(\omega=\mathbf{- 0 . 9 0})$. The observed maximum queue length is $1.2 \mathrm{~km}$ while the most closely approximated result is the Greenshield model with 0.9 $\mathrm{km}$. So the model that best to represent the field conditions is the Greenshield model.
\end{abstract}

Index Terms - Volume, Speed, Density, Shock Wave, Bottleneck

\section{INTRODUCTION}

$\mathrm{T}$ RANSPORTATION problems are a problem faced by developed countries and developing countries such as Indonesia. One of the transportation problems is a traffic jam, according to MKJI 1997 traffic jam is a situation where traffic flow exceeds road capacity causing a queue of the vehicle. Congestion for urban road networks often occurs at intersections, especially the intersections of sites and locations that have the potential for a bottleneck. This study discusses the transportation problems caused by road narrowing. Road narrowing is a part of the road with a condition of lower traffic capacity (downstream) smaller than the upstream. Road narrowing leads to an uninterrupted flow of traffic (Interrupted Flow) resulting in decreased speed and increased density between vehicles. The location of the research was conducted at Jalan Let. Jend. Jamin Ginting Km.14.5 with a systematic bottleneck type. Geometrically, the upstream of the road consists of 2 lines, four lanes (with median) and then narrowed downstream (downstream) into two lines, two lanes (without median). The purpose of this study is to get a model that can describe the location of the case study as well as obtaining data in the length of the vehicle queue and the normalization time required to remove the line from the selected model.

Accordingly, the purpose the research is as follows:

1. To know the relationship between volume, speed (speed) and density (density) of traffic due to the occurrence of road narrowing at the study site.

2. Determine the maximum density value on the normal road segment and the narrowed road segment at the study location. 3. To know the value of shock wave due to the narrowing of road at study location.

\section{LITERATURE REVIEW}

Mathematical Relation between Volume, Speed and Density $V=S \times D$

where:

$\mathrm{V}=$ Volume

$\mathrm{S}=$ Speed

$\mathrm{D}=$ Density

Four types of models of mathematical relationships between the three parameters, namely:

TABLE I

GREENSHIELDS MODEL

\begin{tabular}{|c|c|c|c|}
\hline Comrehtion & Equation & Correhtion & Equation \\
\hline S-D & $\mathrm{S}=\mathrm{S}_{\mathrm{ff}}-\frac{\mathrm{S}_{\mathrm{ff}}}{\mathrm{D}_{j}} \cdot \mathrm{D}$ & $\mathrm{V}_{\mathrm{M}}$ & $\mathrm{V}_{\mathrm{M}}=\frac{\mathrm{D}_{\mathrm{j}} \cdot \mathrm{S}_{\mathrm{ff}}}{4}$ \\
\hline $\mathrm{V}-\mathrm{D}$ & $\mathrm{V}=\mathrm{D} \cdot \mathrm{S}_{\mathrm{ff}}-\frac{\mathrm{S}_{\mathrm{ff}}}{\mathrm{D}_{j}} \cdot \mathrm{D}^{2}$ & $\mathrm{~S}_{\mathrm{M}}$ & $\mathrm{S}_{\mathrm{M}}=\frac{\mathrm{S}_{\pi}}{2}$ \\
\hline $\mathrm{V}-\mathrm{S}$ & $\mathrm{V}=\mathrm{D}_{\mathrm{j}} \cdot \mathrm{S}-\frac{\mathrm{D}_{j}}{\mathrm{~S}_{\mathrm{ff}}} \cdot \mathrm{S}^{2}$ & $\mathrm{D}_{\mathrm{M}}$ & $\mathrm{D}_{\mathrm{M}}=\frac{\mathrm{D}_{j}}{2}$ \\
\hline
\end{tabular}

TABLE II

SUMMARY OF THE GREENBERG MODEL EQUATIONS

\begin{tabular}{|c|c|c|c|}
\hline Commation & Equation & Correhtion & Equation \\
\hline $\mathrm{S}-\mathrm{D}$ & $\mathrm{S}=\mathrm{S}_{\mathrm{M}} \operatorname{Ln} \frac{\mathrm{C}}{\mathrm{D}}$ & $\mathrm{V}_{\mathrm{M}}$ & $\mathrm{V}_{\mathrm{M}}=\frac{\mathrm{C}}{\mathrm{be}}$ \\
\hline $\mathrm{V}-\mathrm{p}$ & $\mathrm{V}=\mathrm{DS}_{\mathrm{M}} \operatorname{Ln} \frac{\mathrm{C}}{\mathrm{D}}$ & $\mathrm{S}_{\mathrm{M}}$ & $\mathrm{S}_{\mathrm{M}}=\frac{1}{\mathrm{~b}}$ \\
\hline $\mathrm{V}-\mathrm{S}$ & $\mathrm{V}=\mathrm{S} \cdot \mathrm{C} \cdot \mathrm{e}^{\frac{-\mathrm{S}}{\mathrm{S}}}$ & $\mathrm{D}_{\mathrm{M}}$ & $\mathrm{D}_{\mathrm{M}}=\frac{\mathrm{C}}{\mathrm{e}}$ \\
\hline
\end{tabular}

Medis Sejahtera Surbakti is with the Department of Civil Engineering, Universitas Sumatera Utara, 20155, Medan, North Sumatera Indonesia (email: author@lamar.colostate.edu).

Kristian Napitupulu is with the Department of Civil Engineering, Universitas Sumatera Utara, 20155, Medan, North Sumatera Indonesia. 
TABLE IV

SUMMARY OF THE UNDERWOOD MODEL EQUATIONS.

\begin{tabular}{|c|c|c|c|}
\hline Comratation & Equation & Correhation & Equation \\
\hline S-D & $\mathrm{S}=\mathrm{S}_{\pi} \mathrm{e}^{\frac{-D}{D_{M}}}$ & $\mathrm{~V}_{\mathrm{M}}$ & $\mathrm{V}_{\mathrm{M}}=\frac{\mathrm{D}_{\mathrm{M}} \cdot S_{\ddot{f}}}{\mathrm{e}}$ \\
\hline V-D & $\mathrm{V}=\mathrm{DS}_{\pi} \mathrm{e}^{\frac{-D}{D_{u f}}}$ & $\mathrm{~S}_{\mathrm{M}}$ & $\mathrm{S}_{\mathrm{M}}=\frac{\mathrm{S}_{\mathrm{\pi}}}{\mathrm{e}}$ \\
\hline V-S & $\mathrm{V}=\mathrm{SD}_{\mathrm{M}} \operatorname{Ln} \frac{\mathrm{S}_{\mathrm{r}}}{\mathrm{S}}$ & $D_{M}$ & $\mathrm{D}_{\mathrm{M}}$ \\
\hline
\end{tabular}

TABLE I

MODEL BELL

\begin{tabular}{|c|c|c|c|}
\hline Comelabion & Equation & Contalation & Equation \\
\hline S-D & $\mathrm{S}=\mathrm{S}_{\mathrm{ff}} \mathrm{e}^{-0.0\left(\frac{-\mathrm{D}}{\mathrm{D}_{\mathrm{N}}}\right)^{2}}$ & $\mathrm{v}_{\mathrm{M}}$ & $\mathrm{V}_{\mathrm{M}}=\frac{\mathrm{D}_{\mathrm{M}} \cdot S_{H E}}{\mathrm{e}^{0.5}}$ \\
\hline V-D & $V=D S_{\not j} e^{-0.2\left(\frac{-D}{D_{N}}\right)^{2}}$ & $\mathrm{~S}_{\mathrm{M}}$ & $S_{M}=\frac{S_{f f}}{e^{0.5}}$ \\
\hline V-S & $\mathrm{V}=\sqrt{2} \mathrm{SD}_{\mathrm{M}}\left(\operatorname{Ln} \frac{\mathrm{S}_{\mathrm{fr}}}{\mathrm{S}}\right)^{0.5}$ & $\mathrm{D}_{\mathrm{M}}$ & $\mathrm{D}_{\mathrm{M}}$ \\
\hline
\end{tabular}

\section{A. Testing Statistics}

The variables tested in this study are the values of $\mathrm{F}$ and $\mathrm{t}$ which are the control tools of the results of statistical analysis, in this case linear regression, by comparing the values of $\mathrm{F}$ and $t$ obtained from the calculation with the value of $F$ and $t$ of the table. The test is said to be true if the value of $F$ and $t$ of the calculation is greater than the table, then the value of R2 ( 0 to 1) which is the coefficient of determination showing how much influence independent variable $(\mathrm{X})$ to the dependent variable (Y).

\section{B. Shock Wave Value}

$$
\omega=\frac{V_{1}-V_{2}}{D_{1}-D_{2}}
$$

Where:

V1 = Upstream flow $\quad$ D1 $=$ Upstream density V2 = Max. Flow Downstream D2 = Downstream density

\section{SURVEY METHODOLOGY}

The study was conducted at Jalan Jamin Ginting Km 14.5 (Fig. 1) where there was road narrowing. Survey is done by manual count method to traffic activity at research location. The survey is done by calculating the number of vehicles and speed at the specified points. The survey was conducted on Sunday, April 30, 2017. Time survey conducted for 6 hours ie; morning (09.00-11.00). noon (12: 00-14: 00), afternoon (16: 00-1800). The results of data observed in the field is the number of vehicles, vehicle speed and side resistance.
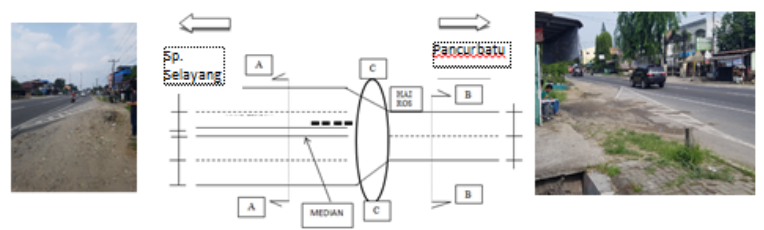

Fig. 1. Study Area at Jalan Jamin Ginting Km 14,5 Medan.

\section{ANALYSIS AND DISCUSSION}

The variable relationship is based on traffic volume data and vehicle speed, taken each 15 minute period arranged in a paired list then the density value can be searched by equation (1). The relationship between velocity (S), density (D) and volume (V), is modeled using four models ie Greenshield, Greenberg, Underwood and Bell models. The completion of statistics is done by finding the relationship between speed and density through the regression method.

The relationship between speed and density of each with Greenshield, Greenberg, Underwood and Bell methods is as follows:

TABLE V

SPEED-DENSITY RELATIONSHIP OF EACH MODEL

\begin{tabular}{|l|l|}
\hline GREENSHIELDS & $\mathrm{S}=22,35863-0,04855 \mathrm{D}$ \\
\hline GREENBERG & $\mathrm{S}=43,664-5,54064 \mathrm{Ln} \mathrm{D}$ \\
\hline UNDERWOOD & $\mathrm{S}=24,864 \mathrm{e}(-0,003083 \mathrm{D})$ \\
\hline BELL & $\mathrm{S}=21,102 * \mathrm{e}\left(-0,5 *(\mathrm{D} / 208,995)^{\wedge} 2\right)$ \\
& \\
\hline
\end{tabular}

\section{A. Determination of Maximum Volume And Model}

TABLE VI

SUMMARY OF REGRESSION ANALYSIS

\begin{tabular}{|c|c|c|c|c|c|}
\hline \multirow{2}{*}{ Location } & \multirow{2}{*}{ Resume } & \multicolumn{4}{|c|}{ Jenis Model Tinjauan } \\
\cline { 3 - 6 } & Intercept & 22,75 & 41,88 & 3,19 & 3,04 \\
\hline \multirow{4}{*}{ Upstream } & & Greenshields & Greenberg & Underwood & Bell \\
\cline { 2 - 6 } & $\mathrm{X}$ Variable & $-0,04$ & $-5,13$ & $-0,00289$ & $-1,13541 \mathrm{E}-05$ \\
\cline { 2 - 6 } & $R^{2}$ & 0,87 & 0,31 & 0,414014 & 0,44500 \\
\cline { 2 - 6 } & $\mathrm{F}$ & 153,70 & 10,07 & 15,54 & 17,64 \\
\cline { 2 - 6 } & $\mathrm{T}$ & 49,07 & 5,74 & 40,61 & 67,20 \\
\hline \multirow{5}{*}{ Downstream } & Intercept & 21,14 & 29,60 & 3,005927 & 2,98 \\
\cline { 2 - 6 } & $\mathrm{X}$ Variable & $-0,04$ & $-2,77$ & $-0,00229$ & $-1,69356 \mathrm{E}-05$ \\
\cline { 2 - 6 } & $R^{2}$ & 0,9463 & 0,89086 & 0,94600 & 0,94602 \\
\cline { 2 - 6 } & $\mathrm{F}$ & 387,96 & 179,57 & 412.12 & 404.08 \\
\cline { 2 - 6 } & $\mathrm{T}$ & 138,28 & 35,14 & 369.20 & 585.08 \\
\cline { 2 - 6 } & $\mathrm{T}$ & 39,28 & 21,85 & 88,87 & 112,43 \\
\hline
\end{tabular}

1. F Value (table): 4,30

2. T Value (table): 2,07

TABLE VII

MAXIMUM VOLUME SUMMARY

\begin{tabular}{|l|c|c|}
\hline Model Lane & Upstream & Downstream \\
\hline Greenshield & 2665,13 & 2527,80 \\
\hline Greenberg & 6593,97 & 44303,82 \\
\hline Underwood & 3115,70 & 3184,04 \\
\hline Bell & 2680,10 & 2066,66 \\
\hline
\end{tabular}

6.794 
Table VI above shows that the largest intercept value is at Greenberg value because it corresponds to the model relationship of the logarithmic form. With the F test value and $t$ test on each segment or the location of the cutoff indicates that each location is greater than the value of $F$ table and $t$ table. Determination of the selected model for the calculation of shock waves is based on the criteria of $F$ test values, $t$ and R2 are large, besides that also seen the maximum current achieved by each model. Underwood and Greenberg models have a large supply value and from the calculation results there is no current coming (demand) exceeds the maximum current value (supply) then of these two models so there will be no shock wave.

\section{B. Calculation of shock waves}

The calculation of shock waves in this road narrowing begins by plotting between the incoming currents (demand) from upstream and downstream capacity ie at the location of the supply narrowing, which is based on the maximum current selected over time. Analysis begins when demand exceeds capacity.

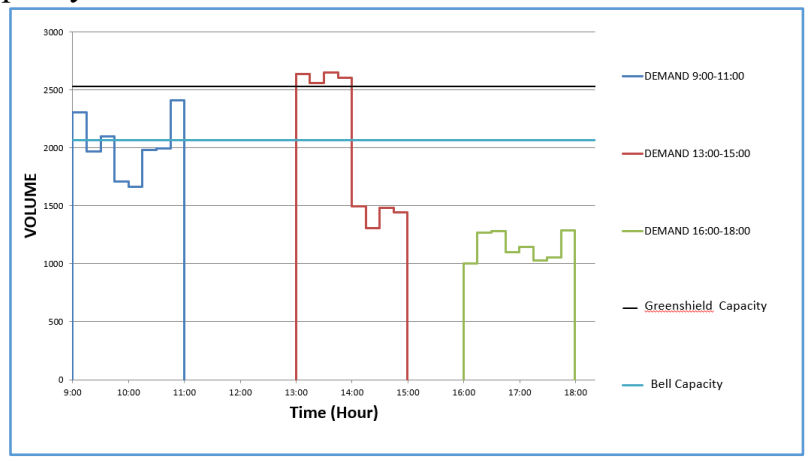

Fig. 2. The relationship of capacity and time

Fig. 2 shows the time when demand across capacities shows that in the Greenshield Model there are four periods when demand exceeds capacity: 13.00-13.15, 13.15-13.30, 13.30-13.45, 13.45-14.00, and on Bell model there are eight periods when demand exceeds capacity, ie: 09.00-09.15, 09.15-09.30, 09.30-09.45, 09.45-10.00, 10.45-11.00, 13.00$13.15,13.15-13.30,13.30-13.45,13.45-14.00$. Based on the observation of the maximum queue length field that occurs as long as: $900 \mathrm{~m}$ or equal to $0.9 \mathrm{~km}$.

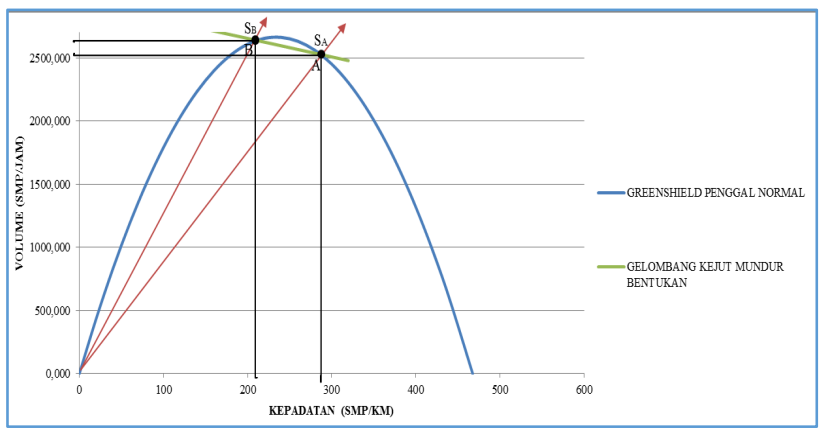

Fig. 3. Shock wave Reverse Format Greenshield Model

Fig. 3 shows where the volume $\mathrm{B}$ is greater than volume A while the B density is less than the density A hence from the large shock waveform $\omega \mathrm{AB}$ is negative. It is shown also in Fig. 4 that the line connecting points $\mathrm{B}$ and $\mathrm{A}$ is towards the lower right (down) condition is called a backward moving shock wave.

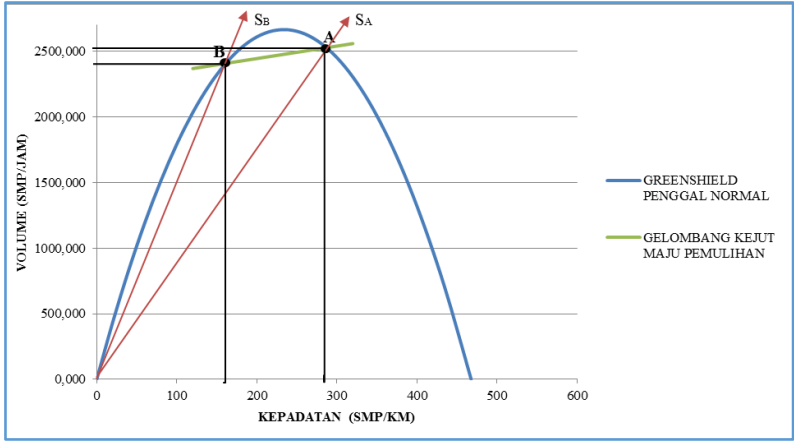

Fig.4. Shockwave Advanced Recovery Model Greenshield

Figure 4 shows where volume $\mathrm{A}$ is greater than volume $\mathrm{B}$ and density $\mathrm{A}$ is greater than density $\mathrm{B}$ then the value of this shock wave is positive. The inclination of the shock wave up to the upper right is to show the value of a positive shock wave moving in the direction of the traffic movement. The shock wave that leads according to this traffic movement is called forward shock shock wave.

\section{CONCLUSION}

From the entire process of observation, calculation and analysis on the traffic flow that occurred on the condition of road narrowing on Jalan Jamin Ginting Km 14.5 from Medan to Pancur Batu can be summarized as follows:

1) There is a significant difference in the speed of travel on these different road conditions, due to the different geometric characteristics of the road, such as from the condition of 2 lane roads to 1 lane. At road condition 2lajur (normal) speed is bigger than with narrow road condition.

2) Maximum volume for each road and each model for Normal Road Conditions: Greenshield Model $\mathrm{Vm}=$ 2665,13; Greenberg Model $\mathrm{Vm}=6593.97$; Underwood Model Vm =3115,70; Bell Model Vm = 2680.10.

3) Maximum volume for each road and each model for the condition of the Road Narrows : Greenshield Model Vm = 2527,80; Greenberg Model $\mathrm{Vm}=44304,82$; Underwood Model $\mathrm{Vm}=3184,04$; Bell model $\mathrm{Vm}=2066,66$

4) Maximum density value for each road and each model for Normal Road Conditions:Greenshield Model Dm = 233.92; Greenberg Model $\mathrm{Dm}=1284.35$; Underwood Model Dm $=346,52$; Bell Model Dm $=209,85$

5) Maximum density value for each road and each model foe the Condition of the Road Narrows: Greenshield Model $\mathrm{Dm}=478.20$; Greenberg Model $\mathrm{Dm}=43445,79 ;$ Underwood Model Dm = 404.35; Bell Model Dm = 171,82

6) The value of the shock wave due to the narrowing of the road at the study site is: Greenshield model there are four periods when demand exceeds capacity, ie: 13.00-13.15 ( $\omega$ $=-1.46), 13.15-13.30(\omega=-0.30), 13.30-13.45(\omega=-$ $1.75), 13.45-14.00(\omega=-0.90)$, and on the Bell model there 
are seven periods when demand exceeds capacity, ie: 09.00-09.15 $(\omega=-1.26), 09.30-09.45(\omega=-0.13)$ 10.45$11.00(\omega=-1.90), 13.00-13.15(\omega=-4.11), 13.15-13.30(\omega$ $=-3.10), 13.30-13.45(\omega=-4.32), 13.45-14.00(\omega=-$ $3.64)$.

The statistical test of both models is Greenshield Model with value $F, t, R 2$ respectively are 3878,$96 ; 138,28 ; 0,9463$ and bell model is 404,08; 585,08; 94602.

Based on the observations, the calculation of the Greenshield model analysis obtained $1.2 \mathrm{~km}$ of queue length while the Bell model obtained queue length $6.9 \mathrm{~km}$ while the observation results obtained maximum queue length: $900 \mathrm{~m}$ or $0.9 \mathrm{~km}$. So the model that fits the actual field conditions is the Greenshield model.

\section{REFERENCES}

[1] Director General of Highways. "Traffic Travel Time Survey and Calculation Guide", Jakarta, 1990.

[2] Y.R. Indrajaya, dan D. Widodo, "Influence of road narrowing to traffic characteristics". Universitas Diponegoro. Semarang, 2003.

[3] A.D. May, "Traffic Flow Fundamentals", Prentice-Hall International Inc, New Jersey, USA, 1990

[4] J. Rudjanakanoknad,. "Analysis of effecting street bottleneck capacity through oblique cummulative plots". Proceeding of the Eastern Asia Society for Transportation Study, Vol 7, 2009.

[5] I. W. Suteja, "Study the relationship of speed, volume and Traffic density with the four model approach". ITB. Bandung, 1998.

[6] O. Z Tamin, "Planning, Modeling, and Transport Engineering," Bandung, 2008.

[7] TRB. Highway Capacity Manual, Transportation Research Board, National Research Council, Washington D.C., 2000. 